\title{
BIODIVERSITY IS BIOGEOGRAPHY: IMPLICATIONS FOR CONSERVATION
}

\author{
By G. Carleton Ray
}

. . the coastal zone, which is the most biodiverse portion of Planet Earth, and within which many conservation problems most urgently lie.
$\mathrm{T}$ HREE THEMES DOMINATE this review. The first is that biodiversity is biogeography. Or, as Nelson and Ladiges (1990) put it: "Indeed, what beyond biogeography is "biodiversity' about?" Second, watershed and seashed patterns and their scale-related dynamics are major modifiers of biogeographic pattern. And, third, concepts of biodiversity and biogeography are essential guides for conservation and management of coastal-marine systems, especially for MACPAs (MArine and Coastal Protected Areas).

Conservation and conservation bioecology have entered into an era of self-awareness of their successes. Proponents of "biodiversity" have achieved worldwide recognition. Nevertheless: "Like so many buzz words, biodiversity has many shades of meaning and is often used to express vague and ill-thought-out concepts" (Angel, 1991), as reflected by various biodiversity "strategies" (WRI, IUCN, UNEP. 1992; Norse, 1993), wherein the overall goals are clear, but in which the "game plan" is not. Furthermore, too little attention is given to biodiversity at all levels from genes to ecosystems (Solbrig, 1991), as well as to how this broad spectrum of diversity may be encapsulated as "the complex mosaic of the variety of life forms on Earth" (Angel, 1991).

This paper focuses on biogeographic pattern at global to subregional scales and on the functional dynamics of keystone species and ecosystems. Emphasis is on the coastal zone, which is the most biodiverse portion of Planet Earth, and within which many conservation problems most urgently lie. I will first describe coastal-zone biodiversity from a static point of view, then take up some ecological dynamics, followed by a discussion of conservation and management implications. Additionally, I will submit that the special features of marine and terrestrial systems are subsumed by the

G. Carleton Ray, Department of Environmental Sciences, University of Virginia. Charlottesville, VA 22903. USA. similarities, as is apparent within the coastal zone, the biodiversity of which depends on land-sea interactions.

\section{"Characteristic Biodiversity"-a Static View}

A complete species inventory for any biogeographic province on Earth is virtually impossible. In fact, species lists, absent a biogeographic frame of reference, can be ecologically meaningless, because such lists say little about the dynamics of environmental change. To address such dynamics, biodiversity is best expressed at a hierarchy of scales, which this discussion follows.

\section{Global Patterns}

Hayden et al. (1984) attempted a summary of the state-of-the-art of global, coastal-marine biogeography at the behest of UNESCO's Man and the Biosphere Programme (MAB) and the International Union for the Conservation of Nature (IUCN). The overall objective was to review coastal-marine biogeographic provinces, following Udvardy (1975) for the land. Purportedly, the result would enable these organizations to incorporate "representative," marine and coastal protected areas into a "global network" of protected areas. A fundamental requirement for any classification is that it should be comprehensive and comparative. Thus our physical classification described reasonably symmetrical oceanic and coastal realms (Fig. 1); that is, the oceanic realms are circumferential and the trailing and collision coasts are generally on the east and west sides of continents, respectively. However, the coastal, biotic provinces, derived largely from Briggs (1974) (Fig. 2) cannot be symmetrical, as endemic flora and fauna differ from place to place and, thus, describe unique provinces, taxonomically speaking.

This classification shows that the coastal zone is geomorphologically and ecologically distinct from both upland areas and the open sea. following Ketchum's (1972) definition that the terrestrial portion of the coastal zone includes the continental plains and the seaward portion includes the continental shelves. The coastal zone has been conformed by the rise and fall of sea level from the 


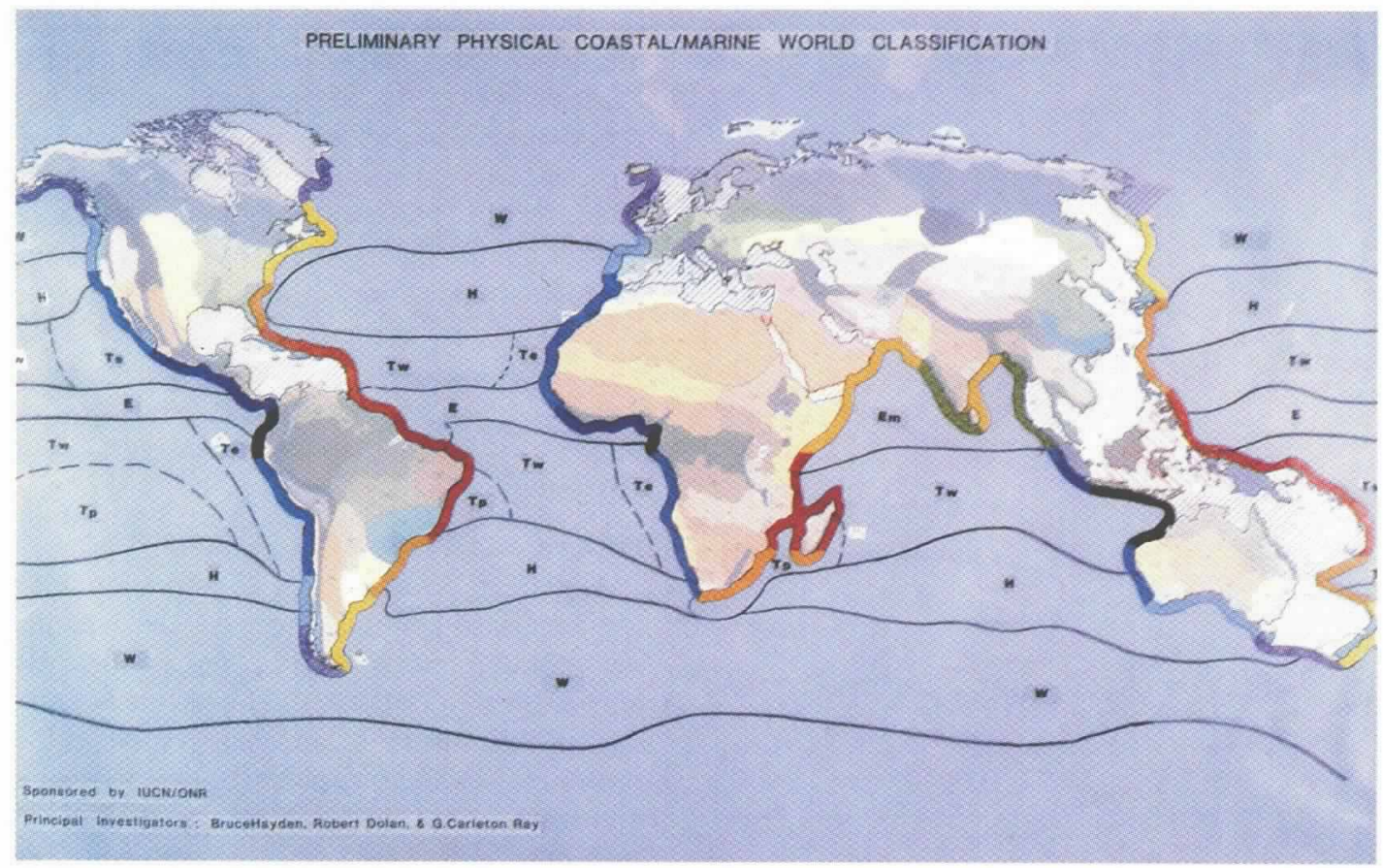

Fig. 1: A global classification of coastal and marine environments. Oceanic areas are indicated by letters. Coastal areas are distinct biogeographically and are shown symbolically as colored bands around the continents. Cross-hatched areas are enclosed seas. Note the general symmetry of both oceanic and coastal areas. See original text for full explanation. From Hayden et al. (1984); terrestrial biogeographic provinces, after Udvardy (1975).

Pleistocene to present (Fig. 3). With respect to biodiversity, this zone has disproportionate global significance. For example, of the approximate 22,000 fish species, about half are restricted to the $8 \%$ of Planet Earth that is coastal zone, whereas $\sim 40 \%$ are freshwater and only $\sim 10 \%$ oceanic (Nelson, 1984), i.e., occurring beyond the continental slope. Other noteworthy coastal-zone species are right, bowhead, and gray whales, many polar sea birds, seals, walruses, and a host of invertebrates.

Another way to address global biogeographic structure, besides biogeographic provinces, is through gradients in species richness. Whether there is a latitudinal gradient in species richness is a matter of debate (Angel, 1991; Clarke, 1992; Rohde, 1992; Rex et al., 1993). At the very least, such gradients are heavily taxon dependent; that is, marine mammals, such as seals, are most diverse in polar regions, whereas fishes are most diverse in the tropics (Ray, 1988). Some taxa have specific requirements favoring low temperatures-e.g., many pinnipeds, cetaceans, and fishes-so that clearly defined gradients in species richness are difficult to evaluate. Comparative biogeographic studies at different latitudes are needed to clarify whether biotic patterns result from historical, evolutionary, behavioral, or physiological factors, or, in all probability, from combinations among them.

From both points of view, it would seem more appropriate to concentrate on what may be termed the "characteristic" diversity of ecoregions and their species assemblages. This would facilitate descriptions of what is special about each region, as well as enable better comparisons among regions inter alia.

\section{Watersheds, Seasheds, Habitats, and Niche}

Subglobally, a biogeographic hierarchy is facilitated by conceiving the coastal zone as an ecotone between land and sea, but one that is distinguished by strong spatial and temporal gradients, both along and across this zone (Ray and Hayden, 1992) and within the water column (Holligan and de Boois, 1993). This zone is uniquely where land, sea, and atmosphere intensely meet. Complex interactions produce a hierarchy of mosaics of habitats, as represented by watersheds, estuaries and lagoons, wetlands, and coastal islands, within which the smallest biogeographic scale is that of the species "niche." Thus both physical and biological approaches are necessary to distinguish hierarchical, biogeographic relationships.

A physical approach is represented by Ray and Hayden (1992), who formulated a simple classification for within-province, coastal-zone structure for defining "coastal units in which the connections among mass, energy, and biota across the coastal zone are stronger than along the coast, especially those that are associated with fluvial interactions" (Fig. 4A). These units allow the identification of several fundamental types of watershed
. . it would seem

more appropriate to

concentrate on what

may be termed the

"characteristic" diversi-

ty of ecoregions and

their species assem-

blages. This would

facilitate descriptions

of what is special

about each region, as

well as enable better

comparisons among

regions inter alia. 


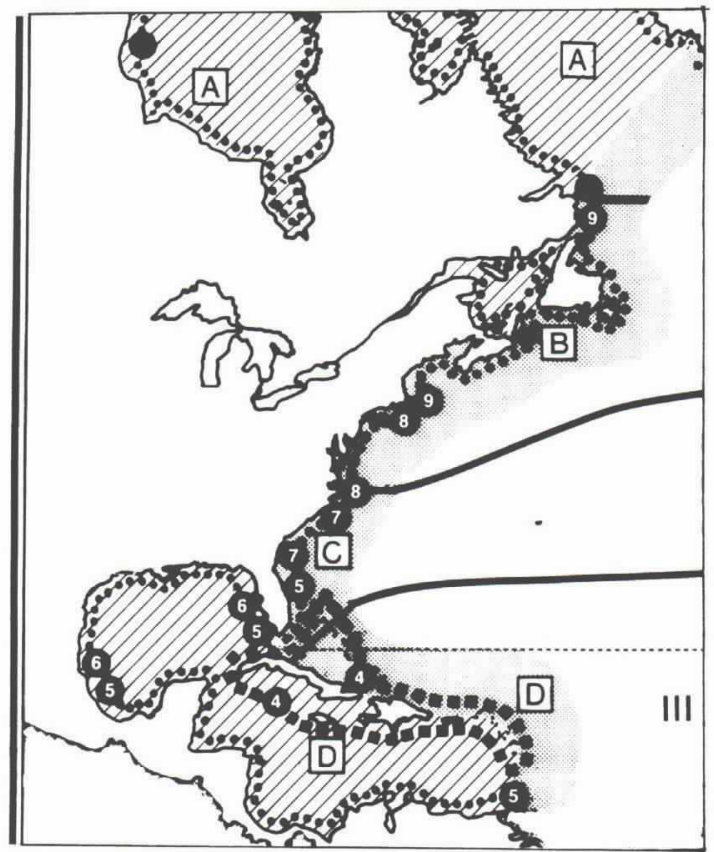

Fig. 2: A coastal-zone classification for eastern North and Central America. Letters indicate physical regions: (A) Subpolar; (B) Eastern temperate; (C) Eastern Subtropical; and (D) Tropical. Numbers are for biogeographic regions after Briggs (1974); (9) Acadian; (8) Virginian; (7) Carolinian; (6) Louisianian; (5) Caribbean, and (4) West Indian. Note that the physical and biogeographic regions reasonably approximate one another. See original text for full explanation. From Hayden et al. (1984).

and receiving basin (coastal seashed) associations (Fig. 4, B and C). This scheme addresses mainly the mesoscale level of organization and has the property of relating coastal unit size and complexity to a variety of processes. Comparisons among types is possible because the units vary in size and dynamics, even though some watersheds may lack certain of the subunits (e.g., rivers in the case of some low-lying, tropical islands).

The biological approach identifies species assemblages. Ray and Hayden (1993) conducted a principal components analysis of 86 "representative" invertebrate and vertebrate species of Beringia and derived seven, statistically significant, biogeographic assemblages (Fig. 5). All of these are distinct, although overlapping, and all are associated with some environmental limiting factor or factors, such as fronts, bathymetry, and other conditions. Our analysis was exploratory, but the method has the possibility of defining offshore "seasheds" from a biotic point of view. It also may be used to define the ecological structure of large marine ecosystems (LMEs) (Sherman et al., 1993), which have tended to be described by factors such as fisheries interactions, productivity, pollution, and the like.
The smallest-scale levels of the biogeographic hierarchy are species-specific habitat and niche. With respect to the former, such habitat types as rocky shore, estuary, lagoon, various types of benthos, etc., appear about equally represented worldwide; that is, there appears to be no gradient in coastal-marine habitat diversity from the tropics to the high latitudes. In fact, habitat diversity may increase in the polar regions due to the complicating effects of seasons and sea ice. The inference is that ecological complexity and habitat variety are not readily related to species diversity and/or ecosystem resiliency.

\section{Pattern and Process-a Dynamic View}

Little can be said about conservation and management until and unless ecosystem dynamics are incorporated into ecological descriptions. For example, Steele (1991) has defined functional diversity as "the variety of different responses to environmental change, especially the diverse space and time scales with which organisms react to each other and to the environment." This approach is concordant with the major theme of the IUBS/SCOPE/UNESCO Diversitas program,

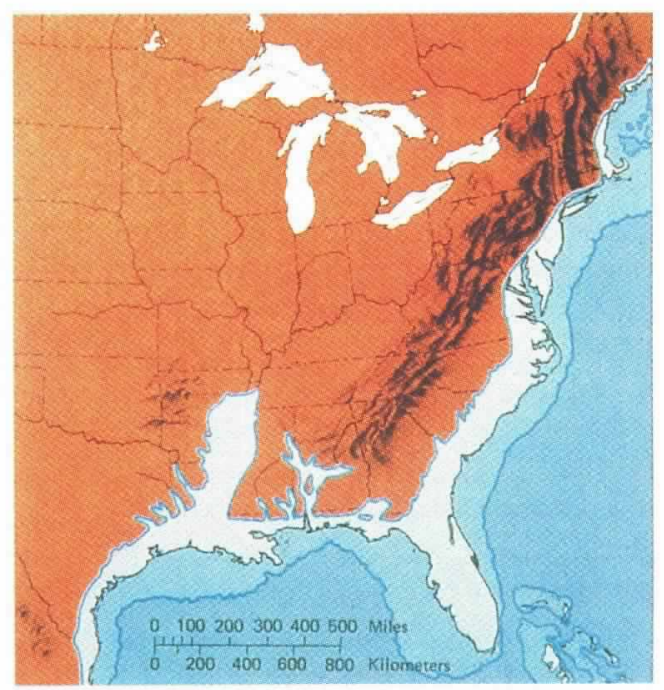

Fig. 3: Rise and fall in sea level of the coastal zone of United States East and Gulf coasts of during the past several million years. This map shows the degree to which the storage of water as glacial ice affects the position of coastlines. The dark blue represents oceanic areas deeper than $130 \mathrm{~m}$ that were unaffected by Pleistocene ice volumes. The mid-blue shows presently submerged areas that were exposed as subaerial plains during low stands of the sea that accompanied maximum advances of Pleistocene ice sheets. The light blue indicates land areas that would be submerged if the present continental ice sheets in Greenland and Antarctica were to melt, thus raising sea level by $\sim 65 \mathrm{~m}$. The coastal zone roughly approximates the mid-blue and light-blue areas. Courtesy Robert Dolan. 


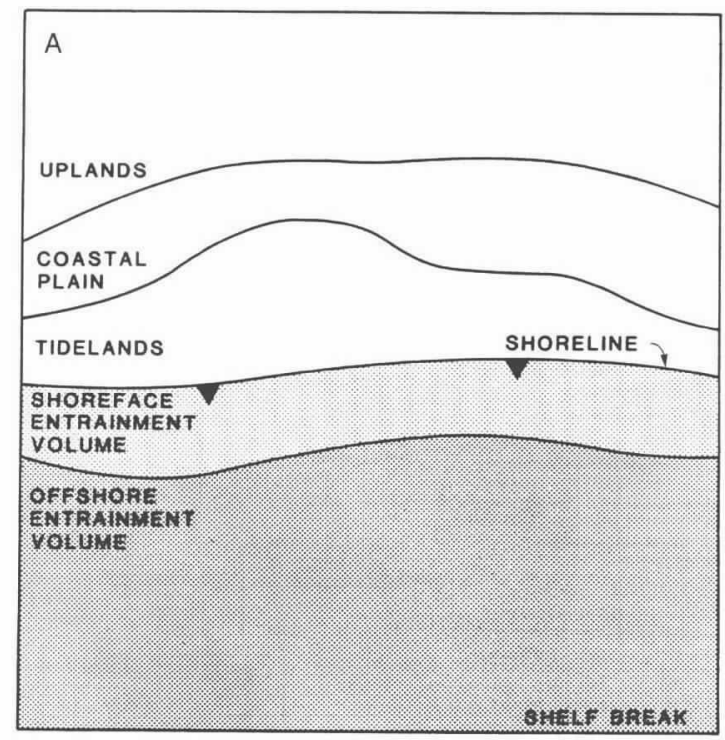

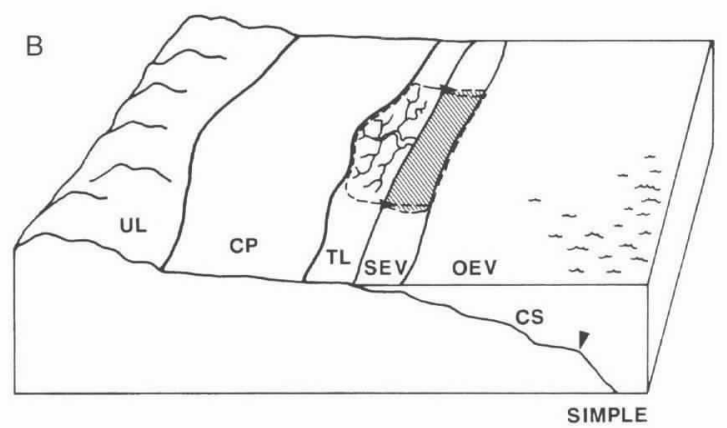

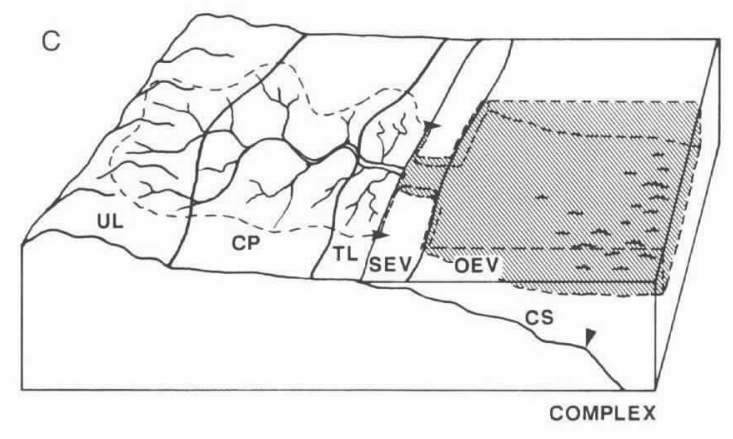

Fig. 4: (A) Structural subdivisions of the coastal zone. Each subdivision is defined by gradients in ecological processes and attributes. (B) Simple type of coastal system in which the flow of water is restricted to tidelands and the shoreface entrainment volume; $(C)$ Complex type of coastal system in which a large drainage system has sufficient flow to bypass the shoreface entrainment volume and drains more or less directly into the offshore volume. Many other combinations are possible due to the sizes, flows, and presence-absence of the structural components. From Ray and Hayden (1992).

which has emphasized that biodiversity may be interpreted in terms of "ecosystem function" (Di Castri and Younès, 1990; Grassle et al., 1991). This view is essential for development of scientific conservation and management strategies. It is exemplified by dynamic biogeography (e.g., Hengeveld, 1990), which incorporates time into the management paradigm, applies synoptic ecology to patterns of distribution, and interrelates small-scale, local attributes of ecosystems to largescale, global ones.

\section{Multiple Biotic Interactions}

The ability of a location to provide suitable habitat for a diversity of species is dependent on an array of physical and biotic factors that vary at different temporal and spatial scales. At the largest scale, the limits of a species' range result from large-scale environmental attributes, such as water-body characteristics, currents, and climate. Combinations of ranges define biogeographic provinces. At smaller scales, each species' distribution (i.e., the apportionment of individuals within the range) is constrained by small-scale habitat patterns and the species' life-history attributes, as is expressed by the concept of niche. It follows that conditions for suitable habitat at different scales represent an hierarchical classification, where the "potential" for species presence is dependent on a set of environmental and habitat requirements defined at those scales. Feedbacks among species and their environments at all scales have the potential to influence the ecological relationships of the system as a whole.

The dynamics of these relationships have been explored for the Virginian and Carolinian provinces of the Eastern United States by Ray et al. (in press). The traditionally accepted boundaries for the Virginian Province are Cape Cod, Massachusetts, to Cape Hatteras, North Carolina, and, for the Carolinian Province, Cape Hatteras to Cape Canaveral, Florida. At these capes, dramatic changes in coastal characteristics, such as water temperatures and circulation patterns, occur. Major differences between these provinces are the sizes, shapes, and hydrological features of rivers, estuaries, and lagoons, and the relative proportions of habitat types, such as seagrass beds, soft bottoms, and oyster reefs. All of these features play major roles in determining different species assemblages.

Our multivariate analysis of estuary-dependent fishes revealed the presence of four large-scale assemblages for these two provinces: 1) Virginian, 2) Carolinian, 3) boreal, and 4) subtropical. For
The ability of a

location to provide suitable habitat for a diversity of species is dependent on an array of physical and biotic factors that vary at different temporal and spatial scales. 

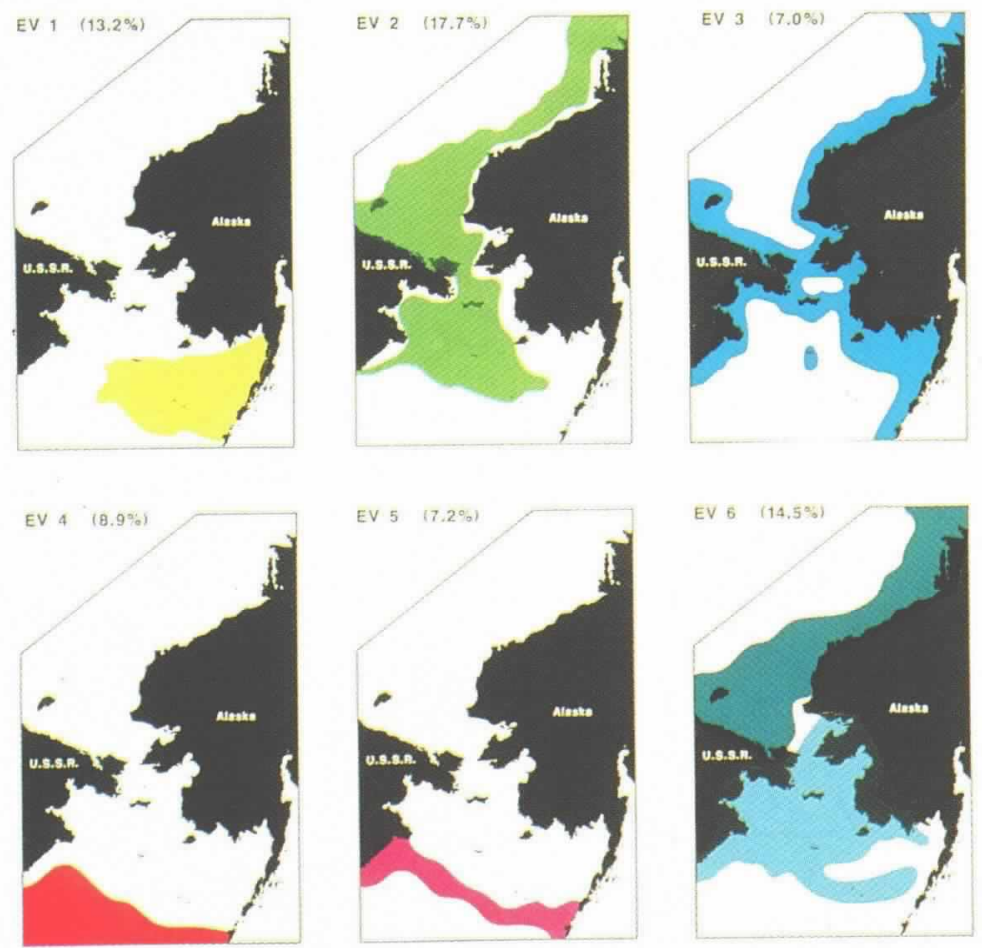

Fig. 5: Beringian biotic assemblages. Range data for 86 representative invertebrate and invertebrate species were subjected to principal components analysis to reveal the following assemblages: (EV1) southeast Bering Sea; (EV2) Beringian shelf; (EV3) Beringian inner shelf; (EV4) North Pacific; (EV5) Bering Sea slope; and (EV6) Chukchi-Beaufort seas shelf/Bering Sea shelf. Percentages represent the variance of the total sample explained by each vector. Taken together, these overlapping assemblages cover $150 \%$ of the entire Beringian shelf region, calling attention to the difficulties in identifying a "hot-spot" for regional conservation. From Ray and Hayden (1993).

the Eastern oys-

ter ... is a classic

example of a key-

stone species of the

coastal-zone ecosys-

tem. from NOAA (1985) resulted in five attributes that each, many species range beyond the points of inflection for the province boundaries. A concurrent analysis of 18 physical-estuarine variables are of consequence to the biota: 1) estuarine dimensions, 2) dominance of marine processes, 3) co-dominance of marine and freshwater processes, 4) fjordlike attributes, and 5) large surface area. Combinations of these and other attributes result in a rich array of East Coast estuaries, each of which supports different assemblages and abundances of species at different times.

The ecological dynamics within these provinces are strongly influenced by the "keystone" role of the Eastern oyster, which builds estuarine reefs that provide the only naturally occurring, hard substrate in an otherwise mobile benthic environment of sand and mud. Oyster reefs affect circulation patterns, tidal flow dynamics, the movements of particles, nutrient exchange, water quality, and the settlement, shelter, and feeding of estuarine species (Wells, 1961; Galtsoff, 1964; Bahr and Lanier, 1981; Denny, 1988; Newell, 1988; Dame et al., 1992; Newell and Breitburg, 1992; Wright et al.,
1992; Childers et al., 1993; Dame and Libers, 1993). In brief, the Eastern oyster appears to form a "heterotrophic hot spot" (Bahr and Lanier, 1981) and is a classic example of a keystone species of the coastal-zone ecosystem.

The implications for the metapopulation dynamics of coastal species are profound. If one accepts that oyster reefs are keystone structures that affect estuarine dynamics, and if one also accepts that estuaries play essential roles in the life histories of coastal species, then it seems inescapable that oyster reefs also help determine the structure of biotic metapopulations for the coastal zone as a whole. A corollary is that, whereas any one estuary may appear to be highly variable on a short time scale, over the large scale of a regional biogeographic province, the metapopulations of coastal species may appear to possess some semblance of "stability." In this sense, estuaries may be conceived functionally as analogous to forest gaps, which are important in structuring forest communities (Shugart, 1984).

Unfortunately, our ability to apply regional "gap" models for the coastal zone is extremely limited. Many of the attributes of estuaries important for coastal biota are not included in NOAA (1985), e.g., small-scale physical properties, productivity, etc. This means that the NOAA data are insufficient to predict estuarine species distributions, except in a very general way. That is, these data may be useful for developing a general, large-scale, physical estuarine classification, but whether they can be used to correlate biotic and physical estuarine characteristics, as has been attempted by Monaco and Lowery (1993) and Monaco et al. (1992), is doubtful. Nevertheless, the strong dependency of many coastal species on estuaries and the apparent functional differences among the estuaries themselves support the conclusion that estuarine function is a major influence on species distributions over the adjacent shelf.

\section{Thresholds, Breakpoints, Discontinuities, and Flips}

Although the concept of "key" elements of ecosystems is relatively well recognized, the concept of the "balance of nature," also expressed as "stability," still strongly lingers in the public mind and often seems to drive conservation and management. This concept assumes that ecosystems have homeostatic properties, incorporating mechanisms that assure dynamic stability, resiliency, predictability, and sustained production of resources. Whereas these assumptions have limited validity, we now know that environments also undergo nonlinear, seemingly chaotic, behavior. Terms such as "threshold," "discontinuity," "breakpoint," and "flip" are used to describe points at which some function or aspect of a system may suddenly be lost. The exact reasons are most often unclear. 
The logic that biodiversity and stability are related began to be seriously challenged about two decades ago, when it became clear that the relationship was complex and many-faceted. Orians (1975) defined stability variously as constancy, persistence, inertia, elasticity, amplitude, cyclical stability. and trajectory stability. As Orians noted, attempts to ". . . find general relationships between stability and diversity are likely to be fruitless" and ". . . it will be difficult to establish causal relationships between stability and diversity because we must measure one or more concepts of stability in ecological systems differing only in some measure of diversity." At about the same time. May (1977) concluded that "natural multi-species assemblages of plants and animals are likely to possess several different equilibrium points." That is, subsequent to a small perturbation, the system may assume a different state. then return to its initial state. However, large disturbances may carry the same system "into some new region of the dynamical landscape . . . ", which implies moreor-less permanent, nonreversible change. For more complex situations, with more and more species, May noted that models become so complex that ". . . the dynamical landscape can begin to look like the surface of the moon." [See Note Added Proof.]

The conclusions are. first. that stability in the sense of fixed, unvarying. constant. enduring, and permanent is not the way ecosystems work. Second, "discontinuities," or alterations described by any other name, are devilishly difficult to define and even worse to predict. Third, although the structures and functions of ecosystems and their biota are coadapted, their ecological time constants may not necessarily match. If important ecosystem components go awry, the result may be species depletion or extinction on the one hand. or simply another structural-functional ecosystem state. The final and major point is that various ecosystem states and disfunctions are describable in terms of dynamic biogeographic change. This is evident in the following examples.

- Alterations produced by the invasion of the Chinese clam Potamocorbula amurensis in California (Butman and Carlton, 1995);

- The deterioration of coral reefs in the Florida Keys and Caribbean Basin (Jackson, 1994);

- The effects of global transportation of nonindigenous marine organisms, with severe disruptions of community structure (Carlton and Geller. 1993);

- The consequences of widespread eutrophication, especially in coastal seas, with effects on species diversity, biomass, and abundance (Gray, 1982): and

- Large-scale shifts in climate that trigger disease outbreaks and that cause the near elimination of top carnivores, with subsequent marked consequences for local community structure (Dungan et al., 1982).
These examples span a spectrum of spatial scales from global to local and temporal scales from long-term to almost immediate. They are but a tiny portion of the coastal-marine perturbations that are presently being witnessed, worldwide. Indeed. if all such perturbations are taken into account. coastal systems, where most of the world's human population lives, are probably as perturbed as any on Earth - and their conservation and management most difficult.

\section{"Hot Spots"-Conservation on the Griddle}

A central question with regard to biodiversity concerns its conservation and management, and one of the primary mechanisms for this is protected areas. Ray and McCormick-Ray (1994) noted "Protected areas may, hypothetically, be said to play a role in the conservation of biological diversity of coastal-marine systems. The questions are: Do they? Can they, in practice? And, at what scale and how completely?"

Hundreds of MACPAs exist worldwide, the preponderance of which are coastal. only a few being truly marine. Agardy (1994) emphasized their potential for multiple use, harvest refugia, testing grounds for conservation biology, ecological studies, and ecosystem management (while also stressing differences among terrestrial and marine systems, about which more below). These are cast as "advances in marine conservation" and well they could-or should-be. However, it seems clear that most such "advances" are promissory notes, yet to be demonstrated. For among MACPAs, no true network exists, research and monitoring are not well developed, and long-term, sustainable, multiple use within harvest refugia has not been demonstrated. The fact is that most MACPAs have been established $a d h o c$ and for a great variety of reasons. Dynamic biogeography has been little considered, if at all. On the contrary, selection of MACPA sites remains dominated by seeking "representative" environments, static descriptors, and the selection of "hot spots."

Recent reviews (Kelleher and Kenchington, 1992; Norse, 1993; World Bank, 1995) present criteria for MACPA selection that are remarkably similar to those of the first International Conference on Marine Parks and Reserves (IUCN, 1976): these include "rare biogeographic qualities," "representative types," "unique or unusual features," "essential ecological processes," "integrity," "endangered species," "nursery or juvenile areas," "feeding, breeding or rest areas," "rare or unique habitat," "genetic diversity," "endemism," and the like. Application of such "hot spot" criteria is fraught with problems. First, they are prescriptions for a static world, one in which environmental change is presumed not to occur, or at least is not made explicit. Second, according to the aforementioned criteria, the whole world is included! Clearly, if one were to include all taxa. all ecolog-
.. if all such per-

turbations are taken

into account, coastal

systems, where most

of the world's human

population lives, are

probably as per-

turbed as any on

Earth-and their con-

servation and man-

agement most

difficult. 

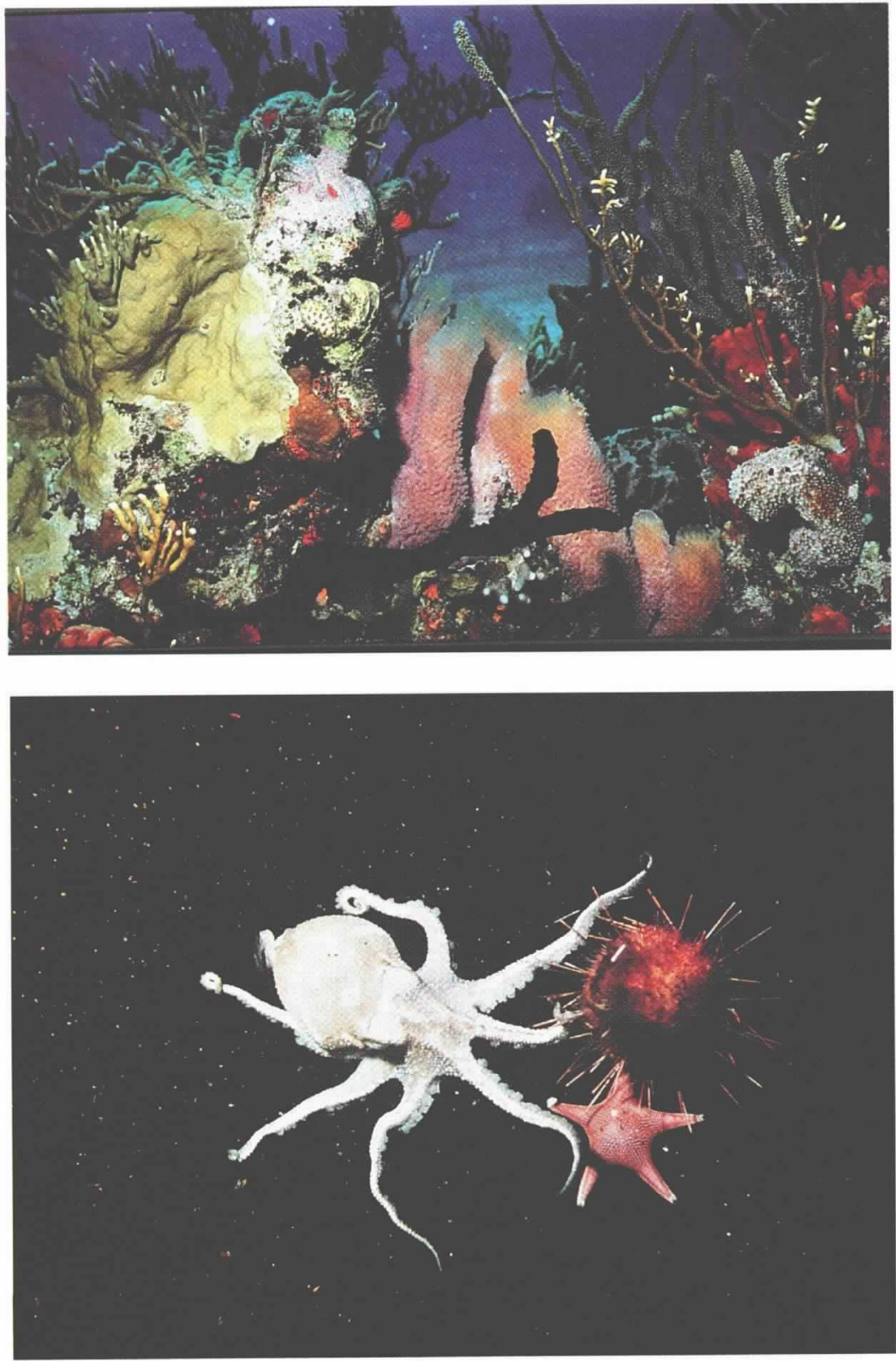

Fig. 6: Top, a tropical-Bahamian reef assemblage. Is this species-rich system more valuable than the assemblage shown below? Bottom, a Southern Ocean assemblage of 3 species from McMurdo Sound, Antarctica: an octopus (Octopus), a starfish (Odontaster), and a sea urchin (Sterechinus). Many endemics are restricted to those waters. Is this system of lesser value than that above? Photographs by G. Carleton Ray.

the entire sur-

face and depths of

Planet Earth provides

so-called hot spots

for some living thing ical processes, and all nursery and other "critical" areas, the entire planet would be covered more than once over! For it is a fact that the entire surface and depths of Planet Earth provides so-called hot spots for some living thing, as a consequence of four-plus billion years of biological evolution. Our analysis of Beringian assemblages (Fig. 5) illustrates this point.

In short, the hot-spot selection process takes little account of ecosystem theory, current thoughts about biogeography, or environmental change. Little recognition is given to the biogeographic dis- tinctness of the coastal zone (Ketchum, 1972; Hayden et al., 1984; Holligan and de Boois, 1993), and for this reason alone, the key criterion of "representativeness" is likely to be misconstrued. Pressey et al. (1993) recognize the need for reserves to "contain as many examples of as many elements of biodiversity as possible," and for "combining sites into representative networks." They suggest three objective, quantitative principles for achieving this goal: complementarity, flexibility, and irreplaceability. Their method is highly dependent on knowing the species that are present_-difficult enough for forests and trees, but almost an impossibility for the many smaller, more mobile organisms of the land or sea. These authors suggest that another starting point may be needed: "The definition of 'representative' needs to be extended to cover, not only examples of land types or populations of species, but the temporal and spatial dynamics being addressed by landscape ecology and metapopulation dynamics."

In sum, the selection of areas to be protected seems often driven by criteria that fragment the web of life. The hot spot as a magic bullet for conservation of biodiversity conceives of the existence of "cold areas" of little worth. This seems odd considering the fact that conservation emphasizes the unity of life, that "sustainability" cannot be attained other than by ecosystem principles, and that no place is valueless. It is especially problematic to assume that known species richness confers higher priority on one area over another. Coral reefs are widely regarded as the wetbiodiversity equivalents of tropical forests. But because they may hold more species, do they, therefore, deserve higher priority than, for the sake of argument, the Southern Ocean (Fig. 6)? Should the tropics be judged more valuable for the species diversity of their coral reefs than the temperate seas for their oyster reefs and fishery production, or the polar regions for their abundances of whales, seals, walruses, penguins, and auklets?

\section{Future Implications}

It is my thesis that the major integrating factor for the ecology, conservation, and management of coastal-marine biological diversity is dynamic biogeography, primarily at the level of the landseascape. This is to say that a species approach is a poor surrogate for ecological function, complexity, resilience to stress, etc., and that species richness is certainly not a reliable measure of conservation priority or "value." Rather, multiscale, functional relationships of coastal watersheds/seasheds and large marine ecosystems provide the context for ecosystem conservation and management. This requires the recognition of hierarchies of scale as a fundamental operational principal. In this context, species' natural history may provide the fundamental links toward greater understanding of complex ecological problems 
(Bartholomew, 1986). That is, greatly increased attention should be given to the specific life-history characteristics that "connect" species ranges to habitat-scale distributions, as I have tried to show in the case of the oyster.

Efforts are now underway to develop international (Grassle et al., 1991; Lasserre et al.. 1994) and U.S. (NRC, 1995) coastal-marine research programs to examine the functional role of marine and coastal biodiversity. NRC (1995) identifies as one of its five major objectives: "to understand the patterns. processes, and consequences of changing marine biological diversity by focusing on critical environmental issues and their threshold effects. and to address these effects at spatial scales from local to regional and at appropriate temporal scales." In this connection, the existence of the coastal zone, which is dominated by land-sea interactions, forces us to challenge much of the mythology of land-sea differences. In fact, the assumption is often made that differences between land and sea are so great that. almost reflexively, their common properties may be ignored. The NRC (1995) has listed "distinctive features of marine ecosystems":

- Marine primary producers are mostly small and mobile, whereas terrestrial ones tend to be large and sessile:

- Large marine predators have a greater range of life-history characteristics, and higher reproductive outputs;

- Biomass of marine systems is thousands to hundreds of times more dilute than for terrestrial systems:

- Marine systems are "open" in the sense of being linked by larval dispersal; and

- The higher order diversity of marine life is substantially richer.

Surely, land and sea are different in many ways, but I have emphasized words that indicate that these "differences" are mostly matters of degree and scale. As for marine systems being "open," NRC (1995) notes that the sea is not just a "vast homogeneous body of water," but has sharp divisions. and that the benthos behaves ecologically similarly to the land. Steele et al. (1989) admitted to land-sea differences in many respects, but concluded that "So far the terrestrial and marine sectors have been considered separately. . . But the critical question is whether the science itself requires this division . . the perceived need to view our world as a single system requires ecological theory and practice to achieve a strong common basis. . . . No single "axis" can bring together the contrasts among marine, terrestrial, and freshwater ecosystems."

In conclusion, it appears self-evident that biodiversity can best be made relevant to conservation and management in ecosystem terms. This is mainly true because most species are currently unknown, and an ecosystem approach is the best way to conserve processes, even though we can never lose concern for the species themselves (Franklin, 1993). The following principles, therefore, apply:

- Coastal-marine biodiversity may best be represented at the level of the land- and seascape. with lesser attention given to species;

- Coastal-marine science and conservation-management must be scaled to regional attributes and processes, with special attention given to land-sea interactions in the coastal zone;

- Models that attempt to predict population fluctuations and the demographics of coastal-marine species should explicitly include the life-history dynamics of key species in their design;

- Criteria for ecological "representativeness" and national or international "significance" will need to be made explicit in terms of the time and space scales of species assemblages and ecological interactions; and

- Networking among scientists and conservation is essential.

I conclude with an emphasis on networking. This has two indivisible components: 1) detailed and intimate communication on issues of both scientific understanding and stewardship and 2) the establishment of comparative methods so that information from individual sites may be ecologically and biogeographically related. As for the science, comparative approaches are possible through the development of a dynamic biogeography for the world's oceans and coastal zones. By such means, regional problems, such as the die-off of the Caribbean sea urchin, Diadema (Lessios et al., 1984) may be evaluated. and the possible global effects of the sea's warming might be linked to coral bleaching (Glynn, 1991). With respect to scientific networking, large-scale, scientific requirements include (Parsons and Seki, 1995): 1) the flows of energy, 2) the recycling of biologically important elements, 3) the life cycles of the biota. and 4) the information within ecosystems in terms of biodiversity. In addition to the science, however, networking must serve to communicate among at least three additional sectors, all with differing viewpoints and time constants: management, conservation, and public policy. Admittedly, science itself can be a significant part of the communication problem, due to its own peculiar culture. On the other hand, much of conservation "seems too divorced from the scientific base from which must come the knowledge it seeks" (Angel, 1991). If the science alone were not difficult enough, the social dynamics of biodiversity may be even more so, making networking possibly our greatest future challenge.

\section{Acknowledgements}

This paper was supported by the Global Biodiversity Fund of the University of Virginia, through
Coastal-marine sci-

ence and conserva-

tion-management

must be scaled to

regional attributes

and processes, with

special attention

given to land-sea

interactions in the

coastal zone 
the generosity of Mrs. Sara S. Brown of Louisville, Kentucky; the Munson and Henry Foundations of Chicago, Illinois; and Edward M. Miller of Charlottesville, Virginia. For the review of estuarine dynamics, B.P. Hayden and M.G. McCormick-Ray were supported, in part, by the Division of Environmental Biology, National Science Foundation Grant BSR 8702333-02. Dr. C.R. Robins, formerly Maytag Professor of Ichthyology, University of Miami. provided essential advice on fishes. Robert Dolan, University of Virginia, kindly supplied Figure 3. Peter Bridgewater, Chief Executive Officer of the Australian Nature Conservation Agency, commented on portions of an earlier draft. M. Geraldine McCormick-Ray of this Department provided extensive comments as well.

Note Added in Proof. Since this paper was written, Tilman (1996) has shown that biodiversity per se may directly be linked to ecosystem sustainability [Ecology 77 (2), 350-363].

\section{References}

Agardy, T., 1994: Advances in marine conservation: the role of marine protected areas. TREE, 7, 267-270.

Angel. M.V.. 1991: Biodiversity in the oceans. Ocean Challenge, 2, 23-36.

Bahr, L.M. and W.P. Lanier, 1981: The ecology of intertidal oyster reefs of the South Atlantic coast: a community profile. U.S. Fish and Wildlife Service. Office of Biological Services. Washington DC FWS/OBS-81/15.

Bartholomew, G.A., 1986: The role of natural history in contemporary biology. BioScience, 36, 324-329.

Briggs, J.C., 1974: Marine Zoogeography. MeGraw-Hill, New York. 475 pp.

Butman, C.A. and J.T. Carlton, 1995: Marine biological diversity: some important issues, opportunities and critical research needs. Rev. Geophysics. Supp. 1201-1209.

Carlton, J.T. and J.B. Geller, 1993: Ecological roulette: the global transport of nonindigineous marine organisms. Science, 261, 78-82.

Childers. D.L. H.N. McKellar, R.F. Dame, F.H. Sklar and E.R. Blood, 1993: A dynamic nutrient budget of subsystem interactions in a salt marsh estuary, Estucirine Coastal Shelf Sci., 36. 105-131.

Clarke. A.. 1992: Is there a latitudinal diversity eline in the sea? TREE, 7, 286-287.

Dame, R., D. Childers and E. Keopfler, 1992: A genhydrologic continuum theory for the spatial and temporal evolution of marsh-estuarine systems. Neth. J. Sea Res., 30. 63-72.

and S. Libers, 1993: Oyster reef's and nutrient retention in tidal creeks. J. Exp. Mar. Biol. Ecol. 171, 251-258.

Denny. M.W., 1988: Biology and the Mechanics of the WaveSwept Environment. Princeton University Press. Princeton, $329 \mathrm{pp}$.

Di Castri, F. and T. Younès, 1990: Ecosystem function of biological diversity. Biol. Int. Spec. Iss.. 22. 1-20.

Dungan, M.L.. T.E. Miller and D.A. Thomson, 1982: Catastrophic decline of a top carnivore in the Gulf of California rocky intertidal zone. Science, 216, 989-991.

Franklin, J.F., 1993: Preserving biodiversity: species. ecosystems. or landscapes? Ecol. Appl. 3, 202-205.

Galtsoff. P.S. 1964: The American oyster Crassostrea virginica Gmelin. Fish. Bull. U.S. Fish and Wildl. Serv., $64,1-480$.
Glynn, P.W., 1991: Coral reef bleaching in the 1980s and possible connections with global warming. TREE, 6 175-179.

Grassle, J.F.. P. Lasserre, A.D. McIntyre and G.C. Ray, 1991 Marine Biodiversity and Ecosystem Function. Biol. Int. Spec: Publ., 23, 19 pp.

Gray, J.S., 1982: Eutrophication in the sea. In: Marine Eutrophication and Population Dynamics. G. Colombo. I Ferrari, V.U. Ceccherelli and R. Rossi, eds. Olsen and Olsen. Fredensborg, Denmark, 3-15.

Hayden, B.P., G.C. Ray and R. Dolan, 1984: Classification of coastal and marine environments. Envir. Cons., 11, 199-207.

Hengeveld, R., 1990: Dynamic Biogevgraphy. Cambridge Univ. Press, Cambridge, UK, 249 pp.

Holligan, P.M. and H. de Boois, 1993: Land-Ocean Interactions in the Coastal Zone (LOICZ): Science Plan. Global Change Rept. No. 25. IGBP. Stockholm. 53 pp.

IUCN. 1976: An International Conference on Marine Parks and Resenes: Papers and Proceedings. IUCN Publ New Ser. No. 37. Int'l Union Cons. Nature and Nat. Res. (now World Conservation Union). Morges (now Gland), Switzerland, $131 \mathrm{pp}$.

Jackson, J.B.C., 1994: Constancy and change of life in the sea. Phil. Trans. Roy. Soc. Lond. B., 344, 55-60.

Kelleher. G. and R. Kenchington. 1992: Guidelines for Establishing Marine Protected Areas. IUCN-The World Conservation Union. Gland, Switzerland, $90 \mathrm{pp}$.

Ketchum, B.K.. ed., 1972: The Water's Edge: Critical Problems of the Coastal Zone. MIT Press, Cambridge, UK. $393 \mathrm{pp}$.

Lasserre, P.. A.D. McIntyre, J.C. Ogden, G.C. Ray and J.F. Grassle. 1994: Marine laboratory networks for the study of biodiversity, function, and management of marine ecosystems. Biol. Int'l Spec. Issue No. 31. Int'l Union of Biol. Sci., Paris, France, 32 pp.

Lessios, H.A., D.R. Robertson and J.D. Cubit. 1984: Spread of Diadema mass mortality through the Caribbean. Science, 226, 335-337.

May, R.M.. 1977: Thresholds and breakpoints in ecosystems with a multiplicity of stable states. Nature, $269,471-477$.

Monaco, M.E. and T.A. Lowery. 1993: Comparative analysis of U.S. East Coast estuaries based on fish and invertebrate distributions and estuarine physical and hydrological characteristics. Estuarine Res. Fed. Abstracts, 12th Int'l ERF Conf. 85.

T.A. Lowery and R.L. Emmett. 1992: Assemblages of U.S. West Coast estuaries on the distribution of fishes. J. Biogeogr., 19, 251-267.

Nelson. G. and P. Ladiges, 1990: Biodiversity and biogeography. J. Biogeogr., $17,559-560$

Nelson, J.S.. 1984: Fishes of the World. Wiley, New York, 523 pp.

Newell, R.I.E. 1988: Ecological changes in Chesapeake Bay: are they the result of overharvesting the american oyster, Crassostrea virginica? In: Understanding the Estuarv: Advances in Chesupeake Bay Research. Proceedings of a Conference. 29-31 March. 1988. Baltimore. MD. Chesapeake Research Consortium Publ. 129. CBP/TRS 24/88. 536-546.

and D. Breitburg, 1992: Oyster Reefs. Chesapeake Bay Strategy for the Restoration and Protection of Ecologically Valuable Species by the Ecologically Valuable Species Work Group of the Living Resources Subcommittee, Annapolis. MD. 61-64.

NOAA, 1985: National Estuarine Inventory: Data Atlas, vol. 1. Physical and Hydrologic Characteristics. NOAA/NOS Strategic Assessment Branch, Washington, DC.

Norse, E.A.. ed., 1993: Global Marine Biological Diversity: A Strategy for Building Conservation Into Decision Making. Island Press, Washington, DC, 383 pp.

NRC, 1995: Understanding Marine Biodiversity: A Research Agenda for the Nation. National Resource Council. National Academy Press, Washington, DC, 114 pp. 
Orians, G.H., 1975: Diversity, stability and maturity in natural systems. In: Unifying Concepts in Ecology. W.H. vanDobben and R.H. Lowe-McConnell, eds. W. Junk, The Hague, Netherlands, 302 pp., 139-150.

Parsons. T.R. and H. Seki, 1995: A historical perspective of biological studies in the ocean. Aquat. Living Resour.. 8, 113-122.

Pressey. R.L., C.J. Humphries, C.R. Margules. R.I. Vane-Wright and P.H. Williams, 1993. Beyond opportunism: key principles for systematic reserve selection. TREE, 8, 124-128.

Ray, G.C., 1988: Ecological diversity in coastal zones and oceans. In: BioDiversity. E.O. Wilson and F. Peter, eds. National Academy Press, Washington, DC, 521 pp. $36-50$.

and B.P. Hayden, 1992: Coastal zone ecotones. In: Landscape Boundaries. A.J. Hansen and F. DiCastri, eds. Springer-Verlag, New York. 452 pp., 403-420. and B.P. Hayden, 1993: Marine biogeographic provinces of the Bering. Chukchi, and Beaufort seas. In: Large Marine Ecosystems: Stress, Mitigation, and Sustainability. K. Sherman. L.M. Alexander, and B.D. Gold. eds. American Association for Advancement of Science Press, Washington, DC. 376 pp.. 175-184.

. B.P. Hayden, M.G. McCormick-Ray and T.M. Smith, in press: Land-seascape diversity of the U.S. East Coast coastal zone with particular reference to estuaries. In: Marine Biodiversity: Patterns and Processes. R.F.G. Ormond and J. Gage, eds. Cambridge Univ. Press. Cambridge. UK

and M.G. McCormick-Ray. 1994: Coastal-marine protected areas - -a moving target. In: Marine Protected Areas and Biosphere Reserves: "Towards and New Paradigm," D.J. Brunckhorst, ed. Australian Nature Conservation Agency, Canberra, Australia, 98 pp., 2-9.

Rex. M.A., C.T. Stuart. R.H. Hessler, J.A. Allen. H.L. Sanders and G.D.F. Wilson, 1993: Global-scale latitudinal pat- terns of species diversity in the seep-sea benthos. $\mathrm{Na}$ ture, $365,636-639$.

Rohde, K.. 1992: Latitudinal gradients in species diversity: the search for the primary cause. Oikos, 65, 514-527.

Sherman. K.. L.M. Alexander and B.D. Gold, eds., 1993: Large Marine Ecosystems: Stress, Mitigation, and Sustainability. American Association for Advancement of Science Press, Washington. DC, $376 \mathrm{pp}$

Shugart. H.H.. 1984: A Theory of Forest Dynamics: The Ecological Implications of Forest Succession Models. Springer-Verlag, New York, $278 \mathrm{pp}$.

Solbrig, O.T., 1991: From Genes to Ecosystems: A Research Agenda for Biodiversity. International Union of Biological Sciences, Paris, France, 124 pp.

Steele, J., S. Carpenter, J. Cohen, P. Dayton and R. Ricklefs, 1989: Comparison of Terrestrial and Marine Ecological Systems. Report of Workshop held in Santa Fe. NM. 14 pp.

Steele, J.H., 1991: Marine functional diversity. BioScience, 41 , $470-474$.

Udvardy, M.D.F., 1975: A Classification of the Biogeographical Provinces of the World. IUCN Occas. Paper No. 18, IUCN, Gland, Switzerland, $49 \mathrm{pp}$.

Wells, H.W., 1961: The fauna of oyster beds, with special reference to the salinity factor. Ecol. Monogr., 31, 239-266.

World Bank. 1995: A Global Representative System of Marine Protected Areas. G. Kelleher, C. Bleakley, and S. Wells, eds. Great Barrier Reef Marine Park Authority, World Bank, and World Conservation Union Environmental Department, World Bank, Washington, DC, vols. I-IV: 219, 93, 147, $204 \mathrm{pp.}$

WRI. IUCN, UNEP, 1992: Global Biodiversity Strategy. World Resources Institute. Washington, DC, $244 \mathrm{pp}$.

Wright, L.D., J.D. Boon, J.P. Xu and S.C. Kim, 1992: The bottom boundary layer of the bay stem plains environment of lower Chesapeake Bay. Estuarine Coastal Shelf Sci. $35,17-36$. 